\title{
Critical Thinking Sub-Skills in English Debate
}

\author{
Liqing Wang \\ Foreign Language Department, ZiJin College of Nanjing University of Science and Technology, Nanjing, China
}

\begin{abstract}
Incorporating the existing theoretical models of critical thinking (CT) with empirical data analysis, this paper proposes an analytical framework for English debate in a Chinese EFL context. The framework divides the core tasks of debate into four stages: information assessment, argumentation, presentation, and reflection. Each stage requires different CT skills and sub-skills. After analyzing the $\mathbf{2 4}$ students' debating and subsequent reflective practice, this paper discusses the key points and difficulties in developing CT skills in the process of English debate and tries to explore the operable teaching methods.
\end{abstract}

Index Terms-CT, CT sub-skills, English debate

\section{INTRODUCTION}

CT (Critical Thinking) refers to use appropriate evaluation criteria to think consciously and make reasonable judgments (Damer, 2006). Arguably one of the most fundamental skills, this ability helps make good, reasonable, and ethical decisions, underlying success in academia and professional careers. In fact, Chinese language learners generally lack the ability of comprehensive analysis and logical thinking (Huang, 1998). In the years following 2010, a tremendous amount of educational effort and research have seen directed at the improvement of students' general CT skills.

As the debate is known to be one of the best methods of honing and applying the skills of CT analysis, completing a debating course has been added to graduation requirements in many universities in China and in turn, British Parliament (BP) debate has enjoyed high popularity in China. Domestic research on CT has mainly focused on how to embed it into courses such as English speech, debate, writing, etc. Moreover, in the field of English debate, the focus of attention has tended to be on the rules, strategies, and importance of debate. However, with a distinct lack of empirical research being undertaken, all of the above studies remain only in the hypothetical stage, making little contribution to our understanding of the process by which CT skills are developed through engaging in English in-class debate.

In classroom instruction, teachers take it for granted that as long as the students advance, refute, and defend claims, they will inevitably be honing CT skills and therefore their CT ability will improve. However, it was the finding of the author that even after a whole semester of attending a course that included both developing and practicing debating skills, students' CT skills remained weak, held back by problems like deficits in explanation, irrelevant arguments, failure of role fulfillment, unclear logic, and problematic or absent structure.

There are lots of questions worth exploring such as the nature of the characteristics of individual debaters' CT skills, how to scientifically evaluate the teaching effectiveness of such CT training, and which pedagogical methods prove most effective in improving students' CT skills. To sum up, the solution to the above challenges needs to be based on a clear evaluation standard of CT skills in debate particularly. Combining the existing CT theories with the practice of English debate learners, this paper answers the following two research questions: (1) What are the CT sub-skills in English debate? (2) Which of the CT sub-skills are the focus of learning and teaching and which prove the most difficult?

\section{RESEARCH METHOD}

\section{A. Theoretical Foundation}

CT skills are defined from the perspective of skill and content, but as yet no generally accepted, comprehensive list of skills that constitutes 'CT Skills' has been formulated (Harrell, 2011). Moreover, a different focus of definition and related research of CT skills has resulted in three significant theoretical models of CT.

Firstly, Facione's Delphi Panel's Dualistic Model (2011) explains relevant skills according to task steps by dividing CT skills into two: the processing of external information (interpretation, analysis, and evaluation) and the information output (inference, interpretation, and self-monitoring).

Secondly, the Ternary Model proposed by Paul and Elder (2006) advocates dividing thinking into eight elements: purpose, question, information, definition, hypothesis, perspective, inference, and enlightenment, and all of them should be measured or examined by ten standards including clarity, precision, accuracy, importance, relevance, integrity, logicality, motivation, scope, profundity, to fulfill the goal of CT training.

In addition, based on the above two models, Wen Qiufang (2009) proposed the hierarchical theoretical model. Her model is characterized by meta CT and CT consisting of cognitive skills and affective dispositions. Cognitive skills include three CT skills i.e. analysis, inference, and evaluation, and correspond to the eight standards which include those of clarity, correlation, logicality, profundity, and flexibility. 
However, the CT skills, no matter how comprehensive they are, vary from subject to subject. In contrast, Sun Min (2017) constructed a framework that combined the characteristics of the above three theoretical models and put forward a new analytical framework (see Table 1), with which, he designed CT sub-skills for persuasive speech in particular. Firstly, Sun classified the six types of CT skills (interpretation, analysis, evaluation, inference, interpretation, and self-monitoring) in the Dualistic Model into three (analysis, inference, and evaluation), consistent with those in Wen's hierarchical theoretical model. Secondly, he absorbed the standards of eight elements especially "purpose" and "perspective" from the Ternary Model. In comparison, his framework simplifies the number of CT skills, and the clarification of each sub-skill is clearer and more operable.

TABLE 1

SUN’S CT SKILLS FRAMEWORK (2017, P.33-34)

\begin{tabular}{|c|c|c|}
\hline & & CT Sub-skills \\
\hline \multirow[t]{5}{*}{ Analysis } & Interpretation & $\begin{array}{l}\text { Interpret the meaning of viewpoint, concept, behavior, symbol, } \\
\text { and rhetoric to eliminate ambiguity }\end{array}$ \\
\hline & Clarification & $\begin{array}{l}\text { Clarify the content, meaning, function, motivation, values, and } \\
\text { rules contained in the information }\end{array}$ \\
\hline & Classification & $\begin{array}{l}\text { Put forward the framework of classification to understand, } \\
\text { describe and summarize the information }\end{array}$ \\
\hline & Comparison & $\begin{array}{l}\text { Compare and distinguish views, concepts, and judgments; } \\
\text { analyze the relation between the whole and the parts }\end{array}$ \\
\hline & Identification & $\begin{array}{l}\text { Check and decompose the reasoning process into } \\
\text { presupposition, premise, and conclusion }\end{array}$ \\
\hline \multirow[t]{4}{*}{ Inference } & Organization & $\begin{array}{l}\text { Identify, search and screen the arguments to support the } \\
\text { conclusion }\end{array}$ \\
\hline & Predictability & $\begin{array}{l}\text { Form diversified solutions to problems and predict possible } \\
\text { results }\end{array}$ \\
\hline & Inference & $\begin{array}{l}\text { Use appropriate inference methods and determine the positions } \\
\text { and views }\end{array}$ \\
\hline & Explanation & $\begin{array}{l}\text { Present concepts, methods, standards, situations to evaluate } \\
\text { one's own or others' interpretation, analysis, evaluation, and } \\
\text { reasoning. }\end{array}$ \\
\hline \multirow[t]{3}{*}{ Evaluation } & Validate inference & $\begin{array}{l}\text { Examine, question, and judge the acceptability and sufficiency } \\
\text { of premises }\end{array}$ \\
\hline & Self-monitoring & $\begin{array}{c}\text { Test personal views and justifications, and reflect on factors } \\
\text { affecting fair and objective judgment like stereotypes, } \\
\text { prejudices, emotions, motives, values, attitudes }\end{array}$ \\
\hline & Self-regulation & Correct problems with reasonable methods \\
\hline
\end{tabular}

\section{B. Teaching Background}

This study is based on the teaching practice of debate courses for second-year English majors. The research data came from 24 learners (6 males and 18 females). All students have completed relevant theoretical knowledge of debate on the MOOC online learning platform such as parliamentary debate rules, topic types, debate positions and responsibilities, evaluation criteria, etc. The course design is divided into three stages: pre-debate stage (before-class), during-debate stage (in-class) and post-debate stage (after-class).

"Before-class preparation for debate entails team discussion and information searching. During the three-hour in-class activities each week, topic explanation, debate practice, feedback, and discussion are covered. The specific arrangements are as follows: In the first week, teachers explain the basic concepts, analyze one particular topic (such as social movement, economy, feminism, etc.), and assign the motion to debate for the following week. Debate practice is held in the second class of the second week. After drawing lots to decide the roles, there are 15 minutes of preparation time before the debate begins, this is followed by teachers' oral feedback and interaction. Each round of debate is videotaped for teachers to review students' performances and reflect on what guidance and feedback would be of constructive help after class. Furthermore, having participated in a debate, students are required after class to write reflection journals and complete questionnaires at the end of the semester" (Liqing, 2021, p. 60).

\section{Data Analysis}

This study explains the relevant sub-skills according to the debate task steps. Firstly, the practical in-class debate is divided into four task stages: information assessment, argumentation, presentation, and reflection, and then the core tasks and specific CT sub-skills of each stage are formulated; According to the video of each debate, teachers' scores, feedback and reflection journals, the analysis framework is finally constructed. The second step is to evaluate the individual learners' CT sub-skills listed in the framework by marking and classifying typical problems and summarizing focus and difficulty to debater's CT development. Finally, the author reflects on debate pedagogy, through classroom discussion, video observation, and students' reflective journals.

\section{CT Sub-SkiLls In EngLish DebAte Practice}


This study takes Sun Min's framework of CT sub-skills as the theoretical basis, dividing the CT skills into three categories: "analysis", "inference" and "evaluation". Based on the debate practice, this study elucidates and merges the specific CT sub-skills involved in each task stage of debate activities.

TABLE 2

CT SKILLS In ENGLISH DEBATE PRACTICE (LIQING, 2021, P. 57-58)

\begin{tabular}{|c|c|c|c|c|}
\hline \multicolumn{2}{|r|}{ Stage } & Core tasks & CT skills & CT sub-skills \\
\hline \multirow{4}{*}{\multicolumn{2}{|c|}{ Before-class }} & \multirow[t]{4}{*}{$\begin{array}{l}\text { Information } \\
\text { assessment }\end{array}$} & Analysis \& evaluation & $\begin{array}{l}\text { Analyze the background of the topic and check the relevance and accuracy } \\
\text { of the information }\end{array}$ \\
\hline & & & Analysis & Analyze the topic type \\
\hline & & & Analysis & Analyze the definition and interpretation of the topic \\
\hline & & & Analysis & Analyze potential issues \\
\hline \multirow{8}{*}{$\begin{array}{l}\text { In- } \\
\text { class }\end{array}$} & \multirow[t]{6}{*}{ Preparation } & \multirow[t]{6}{*}{ Argumentation } & Analysis and evaluation & Build the case \\
\hline & & & Analysis & Analyze the burden of proof \\
\hline & & & Inference & Make claims or arguments \\
\hline & & & Inference & Provide reasons and linkage to help reach the conclusion \\
\hline & & & Analysis & Predict the opposite view \\
\hline & & & Evaluation \& analysis & Establish criteria to judge arguments. \\
\hline & \multirow[t]{2}{*}{ Debate } & \multirow[t]{2}{*}{ Presentation } & Analysis and inference & Rebuild the arguments \\
\hline & & & Inference \& evaluation & Respond to refutation, opposing views. \\
\hline \multirow{6}{*}{\multicolumn{2}{|c|}{ after-class }} & \multirow[t]{6}{*}{ Self-evaluation } & Evaluate & Evaluate the structure of the argument \\
\hline & & & Evaluate & Test the relevance of the claim to the conclusion \\
\hline & & & Evaluate & Check the acceptability of claims \\
\hline & & & evaluate & Evaluate the sufficiency of claims for the truth of the conclusion \\
\hline & & & Evaluate & Check the completion of team goal \\
\hline & & & Evaluate & Test the validity of refutation \\
\hline
\end{tabular}

\section{A. Before-Class Preparation}

The instructor announces the motion one week in advance, explaining the relevant background knowledge related to it, and then debater learners work in pairs to search for information and think deeply about the topic through discussion.

"debate topics do not exist is in a vacuum" (Trapp, 2016, p. 45). The topic originates from specific realistic problems in reality. Only by understanding the social and historical background of the topic can the debater clarify the core events of the whole debate. This requires learners to test the relevance, accuracy, and profundity of information and topics. At the same time, the collection of information requires debaters to take the breadth and depth of an issue into account, that is, to consider issues from multiple perspectives, such as both positive and negative sides, from the perspective of different stakeholders and so on. However, it is often the case that the debaters' arguments are single, one-sided, and have little relevance to the topic. The main reason for this was found to be that they had only generated arguments in favor of a position they were in support of rather than researching valid reasons for both sides of an argument. This behavior was combated by the teacher in the pre-debate class releasing only the motion or topic but not allowing pupils to know which side of the argument they would be assigned to. This forces the learners to consider and prepare relevant information which would support both the pro and con sides of the argument. As student Chen reflected, "since there were only 15 minutes to prepare for the on-site competition, even if the teacher emphasized the importance of analyzing the topic background, under the pressure of such time constraints I felt unable to, as my concern was focused entirely on defending my side of the argument. In other words, I was only worried about making my side of the argument sound good. Yet, when the motion was announced a week in advance, I had to consider all perspectives on the motion because I didn't know in advance whether I would be assigned to the pro or anti side. Instead of thinking "what are my arguments?", I thought "what are the core issue of this motion?" "What are the main reasons for people supporting and opposing it?" and "What kind of solution can solve this problem?". Keeping these questions in mind can exercise students' ability to identify, clarify and explain problems by relevance and accuracy.

In addition, debaters need to analyze the types of motion, "to determine what type of motion they are dealing with and how the topic influences the kinds of arguments that will be debated" (Trapp, 2016, p. 46). Take the topic "the advertising image of CK model Jari Jones is not a social advance" as an example, this motion attributes "social progress" to the image of a model and thus is a value motion. Initially, all the learners need to define the core concept of "social advance", and interpret what behavior belongs to "social progress" to narrow the motion. Through selecting appropriate resources and formulating searches, the debaters gradually make it clear that the stakeholders mainly involved in this motion are the minority - the marginalized LGBT group. By combing the historical and social background of this topic, that is, the western model industry, they realize that the core issue in this debate is "the image of an LGBT model conflicting with the traditional image of a model".

After considering the topic background, the type of motion, and the particular definition and interpretation, the debaters then turn to an analysis of the potential issues, say, criteria and application. The first stock issue requires debaters to find a standard or a measure to evaluate something i.e. what criteria should be used to judge whether or not the "social progress" can be assigned to "the image of a model". Guided by these criteria, students can focus their discussion on areas like political correctness, aesthetic standards, model identity. The second stock issue then asks debaters to determine how 
the image of the CK model meets or does not meet the aesthetic standard, whether the way the CK company selects models is according to political correctness, and whether Jari Jones' identity as LGBT meets or does not meet the model identity. In this process, debaters' analytical skills are well trained by identifying the central problems, comparing similarities and differences, and distinguishing relevant information.

\section{B. In-Class Debate Practice}

In this stage, once the draw is released, the debate process models the procedure for the formal debate in parliamentary systems of government, consisting of preparation and on-site debate competition. In the 15-minute preparation time, with the role assigned, debaters' analysis of the topics is also different from the before-class preparation stage. Each debater needs to fulfill his / her duties and obligations. For example, the prime minister needs to define and interpret the topic, while the whip needs to summarize the whole debate. While every debater has his responsibility, each Proposition and Opposition team is subtly competing against the other team on their side.

Since at this stage, every debater is fully aware of their position and roles, the real argumentation, the process whereby debaters employ arguments to advocate a position starts. First, team members need to analyze and build their case such as taking the current situation into consideration, positions and objectives, specific plans (Policy), and standards (value) according to the type of topics and speaker- position. Secondly, team members need to analyze the burden of proof in this debate based on the topic type and stakeholder. Policy topics need debaters to clarify the legitimacy, effectiveness, advantages, and disadvantages of the policy; A value motion would require them to distinguish the object to be evaluated, determine the standard to measure the object, and judge whether the evaluated object meets the standard.

The process of the debate then enters its most important stage, the construction of argument, that is, the process of using relevant and reliable arguments to prove a conclusion through reasoning. Those who do well in argumentation reveal excellent CT skills, namely, inference, analysis, and elevation. Generally speaking, a complete argument consists mainly of three basic elements: claim, evidence, and warrant. First, in the process of preparing arguments, for one thing, debaters need to refine claims, select authoritative and relevant evidence and provide warrants to connect evidence to claims. For another, they also need to predict the arguments and possible refutations that the opposition may put forward. Second, to defend their position, debaters need to put forward the criteria to judge the argument according to the topic type, and then compare the criteria and explain why this particular criterion matters. The most difficult part is the second point. As student Wang mentioned in his journal: "in the process of making an argument, due to limited time, I can only prove why this claim is true by explaining the mechanism, but fail to demonstrate why such a criterion is more important."

Debaters, after prep-time, start to debate. Even though they might be well-prepared, in an actual debate competition, debaters take the risk that another person will confront their argument and that lower houses take the risk that their arguments are discussed in advance by the upper house. In a debate, these risks are almost certainties. Due to the unpredictability of the scene, the claims, evidence, and argument to be expressed by the debaters may be different from the previous predictions. Therefore, speakers may be put in the situation of refuting the opposing side's argument while needing at the same time to rebuild their own, which again develops debaters' skills of inference, analysis, and elevation.

Debate fosters excellence in speaking and CT, but success in a competitive debate depends primarily on good critical listening and note-taking skills. Many debaters only care about whether they have delivered what they have prepared, rather than respond to the opposing teams' strong points. In such a situation, there may not be any engagement between the two sides for the entire debate, nor any new arguments from the lower house. Many students have reflected on this point after practice. For example, classmate Zhou said, "I was trying to listen, but I could only catch the individual keywords, and sometimes, their poor logic stopped me from listening. Thus, instead of listening, my attention shifted to my speech." This kind of feedback is illuminating on providing evidence that weak language competence also hampers the listener from being able to decipher information from the opposing side, thereby limiting their opportunity for developing better CT skills. Indeed, Poor listening ability also explains why students are relatively reluctant to use points of information for direct exchange which offers speakers precious chances to engage a potential weakness or lack of clarity regarding the argument that is being presented. Listening is not a passive activity. Rather, it is an active process and good listening habits and note-taking requires effort and energy and are thus worth special attention in classroom instruction.

In addition, time organization skills are imperative. Some students spent more than three minutes on rebuttal which leaves them no time to rebuild their arguments. No matter how excellent the rebuttal speech is, one team cannot win the debate simply because their arguments are not successfully rebuilt without sufficient evidence to support the claim. The way to improve it is to record the speech to check the time allocation for refutation and reconstruction of the argument and repeat delivering the speech again till they can manage time reasonably. Student Yang, one of the best in class who adopted this method said that it "helped my speech to be structurally sound and better qualified within 7 minutes and 15 seconds". With continuous effort, she managed to break in one tournament.

\section{Reflection Stage}

The reflection stage refers to the debater's self-evaluation, after the on-site debate and the teacher's oral feedback. On numerous occasions, debate learners committed errors repeatedly, making it difficult for them to make progress. In view of this, teachers can ask debaters to reflect after each round of debate practice in written form as required. To be specific, the reflective journals must re-examine speech from the perspectives of the structure of argument, the relevance between 
claims and conclusion, sufficiency and acceptability of claims, and acceptability, and effectiveness of rebuttal and completion of the team goal.

The purpose of writing reflective journals is to engage learners in assessing the quality of their speeches regularly after careful consideration. After all, "thinking is not driven by answers but by questions" (Paul \& Elder, 2006, P. 84). Debaters need to think about questions like "Whether their arguments target at the core of this motion?" "Are claims consistent and acceptable throughout the presentation?" "Is the relevance of the argument guaranteed?"; "Is there a logical fallacy in reasoning?" "Is it clearly and well organized?" "Do the arguments help to achieve the team's goals?" "Do I refute the other's strongest argument?" etc. Questions stimulate thought and answers to them are also an effective means to improve students' awareness and evaluation skills.

The vast majority of students $(87 \%)$ said that such a reflective journal was time-consuming but very helpful. "The reflection journal helps me to re-examine my speech and clarify why I lost the game. While thinking over the judge's oral feedback, I knew that I didn't understand many basic concepts such as "mechanism". When the teacher explicitly asked me to write my own errors in the reflection journal, I went to re-read the relevant parts."; "A Reflective journal is not designed to write feelings as a debater but to think in the way that teacher requires. This forced me to evaluate my way of thinking during the whole process of argumentation."; "During the debate, I thought I was well prepared and quite fluent in delivering my speech, but I still lost this debate. I felt a little disappointed. It was through the process of writing the reflective journal that enabled me to realize that I spent too much time giving examples while failing to demonstrate why these examples mattered". These words show that reflective journals can be useful only if debaters write as required in the way of answering the required questions.

\section{CONCLUSION}

This study, inspired by CT theories combined with classroom debate practice, clearly lays out CT sub-skills that learners need to use at each stage of English debate. In the pre-debate stage of before-class, the core task for debaters is information assessment which requires debaters to adopt analysis and evaluation sub-skills. The key to this stage is to avoid unilateral and irrelevant arguments. During the in-class stage, after each debater knows his or her position and particular role, argumentation starts. Greater emphasis has been given to the construct of argument, which involves sub-skills inference, analysis, and evaluation. However, it is the argument rebuilding and refutation skills that are of paramount importance, because the real debate is full of unpredictability. Moreover, listening and time management skills stand as the foundation upon which debaters can bring all their skills into full play. Finally, and still, a very important factor is the process of after-class self-evaluation. It has become very evident that debaters who evaluate their performance in debate and analyze key questions and problems clearly and precisely help train their evaluation skills and cultivate problem-solving abilities.

Some teaching methods are also put forward to help cultivate CT sub-skills. First, at the stage of information assessment, teachers can announce the motion in advance without assigning roles. Secondly, team discussion on motion type analysis is the key to preventing debaters from veering off the topic. Thirdly, reflective journals which require debaters to reflect upon their thinking process as required enable them to hone their argument skills.

This paper provides illumination and a deeper understanding of what sub-skills constitute CT skills in English debate and which CT sub-skills are the focus and difficulty of classroom instruction. It is hoped that this study can assist teachers in integrating CT into English debate. The training process of CT is long. Only by constantly improving students' understanding of CT and integrating CT training into daily classroom teaching can English teachers cultivate students with excellent language quality and thinking ability.

There are still many deficiencies in this study, such as the lack of consideration of CT disposition, the lack of a more specific and detailed description of CT sub-skills, the narrow scope of data collection, and so on. It is hoped that more teachers will devote themselves to the empirical research of CT skills, working together to improve our understanding of the characteristics of individual debaters' CT skills, and figure out pedagogical methods to improve students' CT skills.

\section{ACKNOWLEDGMENTS}

The author would like to thank Research on philosophy and Social Sciences in Colleges and Universities in Jiang Su Province for funding this research project under grant number 2021SJA2255.

\section{REFERENCES}

[1] Damer. Edward.T.(2008). Attacking faulty reasoning: A practical Guide to Fallacy-free Arguments, Sixth Edition. Belmont: Wadsworth Publishing.

[2] Facione, P. A. (2011). CT: What It Is and Why It Counts. Millbrae, CA: Measured Reasons and the California Academic Press.

[3] Harrell, M. (2011). Argument diagramming and CT in introductory philosophy. Higher Education Research \& Development, 3, 371-385.

[4] Huang Yuanshen.(1998). Si Bian Que Shi [Deficiency of Speculative Thinking Ability]. Foreign language and foreign language teaching, 7, 1-19.

[5] Richard, Paul. \& Linda, Elder. (2006). CT: Learn the Tools the Best Thinkers Use. Pearson/Prentice Hall. 
[6] Sun, Min. (2017). Zhong Guo Gao Xiao Ying Yu Yan Jiang Xue Xi Zhe Si Bian Neng Li Fa Zhan Ge An Yan Jiu The development of critical thinking ability of English speech learners in Chinese colleges and universities. Beijing: Foreign Language Teaching and Research Press.

[7] Trapp, Robert. (2016). Building global relations through debate. Beijing: foreign language teaching and Research Press.

[8] Wen, Q.F. (2012). Zhong Guo Wai Yu Lei Da Xue Sheng Si Bian Neng Li Xian Zhuang Yan Jiu. [Research on the Critical Thinking Ability of Foreign language College students in China Research]. Beijing: Foreign Language Teaching and Research Press.

[9] Liqing, Wang. (2021). A Case Study on the Development of Chinese EFL Debaters' Argumentative Competence. Studies in English Language Teaching, 9(4), 56-68

Liqing Wang was born in Nanjing, China in 1979. She received her graduate degree in linguistics from Yang Zhou University, China in 2006.

She is currently a lecture in the Department of Foreign Languages, ZiJin College of Nanjing University of Science and Technology, Nanjing, China. Her research interests include second language acquisition and English debate. 